\title{
Photoinhibition and photoprotection in symbiotic dinoflagellates from reef-building corals
}

\author{
Ove Hoegh-Guldberg*, Ross J. Jones \\ School of Biological Sciences, Building A08, The University of Sydney, New South Wales 2006, Australia
}

\begin{abstract}
Pulse-amplitude-modulation fluorometry and oxygen respirometry were used to investigate diel photosynthetic responses by symbiotic dinoflagellates to light levels in summer and winter on a high latitude coral reef. The symbiotic dinoflagellates from 2 species of reef-building coral (Porites cylindrica and Stylophora pistillata) showed photoinhibitory decreases in the ratio of variable $\left(F_{v}\right)$ to maximal $\left(F_{\mathrm{m}}\right)$ fluorescence $\left(F_{\mathrm{v}} / F_{\mathrm{m}}\right)$ as early as 09:00 $\mathrm{h}$ on both summer and winter days on the reefs

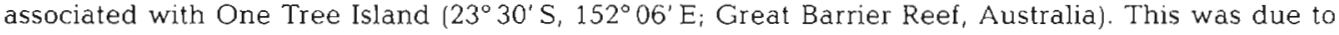
decreases in maximum, $F_{\mathrm{m}}$, and to a smaller extent minimum, $F_{0}$, chlorophyll fluorescence. Complete recovery took 4 to $6 \mathrm{~h}$ and began to occur as soon as light levels fell each day. Chlorophyll fluorescence quenching analysis of corals measured during the early afternoon revealed classic regulation of photosystem II (PSII) efficiency through non-photochemical quenching (NPQ). These results appear to be similar to data collected for other algae and higher plants, suggesting involvement of the xanthophyll cycle of symbiotic dinoflagellates in regulating the quantum efficiency of PSII. The ability of symbiotic dinoflagellates to develop significant $N P Q$, however, depended strongly on when the symbiotic dinoflagellates were studied. Whereas symbiotic dinoflagellates from corals in the early afternoon showed a significant capacity to regulate the efficiency of PSII using NPQ, those sampled before sunrise had a slower and much reduced capacity, suggesting that elements of the xanthophyll cycle are suppressed prior to sunrise. A second major finding of this study is that the quantum efficiency of PSII in symbiotic dinoflagellates is strongly diurnal, and is as much as $50 \%$ lower just prior to sunrise than later in the day. When combined with oxygen flux data, these results indicate that a greater portion of the electron transport occurring later in the day is likely to be due to the increases in the rate of carbon fixation by Rubisco or to higher fluxes through the Mehler-Ascorbate-Peroxidase (MAP) cycle.
\end{abstract}

KEY WORDS: Corals - Symbiotic dinoflagellates - Chlorophyll fluorescence P Photoinhibition · Pocilloporin Colour morphs

\section{INTRODUCTION}

Coral reefs thrive in the shallow sunlit seas of the tropics. The high levels of solar radiation that are characteristic of this environment are important both as an energy source and as a physiological challenge to the organisms that live there (Shick et al. 1996). Reefbuilding corals are no exception, with light being essential to their dinoflagellate symbionts (Symbiodinium spp.), yet posing a potential problem to both host and symbiont. Short wavelength radiation (290 to

·E-mail: oveh@bio.usyd.edu.au
$400 \mathrm{~nm}$ ) has been shown to have a variety of destructive effects on marine organisms (Jokiel 1980), including corals and their symbiotic dinoflagellates (Shick et al. 1996). Effects of ultraviolet (UV) radiation on cultured symbiotic dinoflagellates include decreased growth rate, cellular chlorophyll a, carbon:nitrogen ratios, photosynthetic oxygen evolution and ribulose bisphosphate carboxylase/oxygenase (Rubisco) activity (Banazak \& Trench 1995, Lesser 1996). Similar effects have been reported for symbiotic dinoflagellates living within cnidarian tissues (Jokiel \& York 1982, Lesser 1989, Shick et al. 1991, 1995, Gleason 1993, Gleason \& Wellington 1993, Kinzie 1993, Banazak \& Trench 1995). Both host and symbiont have been reported to have a range of protective mecha- 
nisms to counteract the direct and indirect influences of UV radiation. These include the production of mycosporine-like amino acids for which a UV absorbing function has been inferred, and a range of active oxygen scavenging systems (for a review, see Shick et al. 1996).

Photosynthetically active radiation (PAR) is also potentially detrimental to photosynthetic organisms. Photosynthetic processes saturate rapidly at relatively low levels of flux. Above these levels, light energy is potentially damaging to the photosynthetic machinery (Walker 1992, Foyer et al. 1994, Long et al. 1994, Osmond 1994). Classically, photoinhibition has been interpreted in terms of 'damage' sustained to photosynthetic systems and was measured originally as a long-lasting decrease in photosynthetic rate (oxygen flux) at high irradiances (Kok 1956). This view of photoinhibition has been developed during the past 40 yr to represent one in which damage is primarily associated with photosystem II (PSII), particularly with the increased loss of the D1 protein of the PSII reaction centre (Walker 1992, Styring \& Jegerschöld 1994, Telfer \& Barber 1994). Recent work, however, has also associated changes in photosynthetic conversion efficiencies with an array of photoprotective phenomena (Osmond 1994) that make the question of what is damage as opposed to the down-regulation of photosynthetic systems equivocal (Long et al. 1994, Osmond 1994). The latter has been referred to as 'dynamic' (down regulation) as opposed to 'chronic' (damage) photoinhibition (Osmond 1994, Osmond \& Grace 1995).

The photoprotective mechanisms associated with dynamic photoinhibition span a wide range of phenomena that are reversible over a range of physiological time scales. Energy-dependent quenching of PSII, for example, may take seconds to come into play and is thought to achieve photoprotection by changing the aggregation of light harvesting complex II (LHCII) particles, or by reversibly deactivating individual PSII reaction centres (Duysens \& Sweers 1963, Schreiber \& Bilger 1987). Other changes may take minutes (e.g. xanthophyll cycle inter-conversions, Long et al. 1994), hours (e.g. changes in the expression of oxygen scavenging components), or days (e.g. developmental changes, Long et al. 1994). These changes decrease redox pressure at various points in photosynthetic electron transport, and act as uncoupling mechanisms between incoming light energy and subsequent redox outcomes. The analogy to the 'Victorian governor' by Walker (1992) is particularly applicable to the current understanding of how increased redox pressure across PSII can ultimately induce negative feedback on light capturing efficiencies in the form of reduced photosynthetic efficiencies and thereby reduced damage from excessive light levels.
Early studies of photosynthetic activity using measurements of oxygen flux and/or incorporation of ${ }^{14} \mathrm{C}$ identified a decrease in the maximum photosynthetic rate $\left(P_{\max }\right)$ at high photon flux rates. Decreases in $P_{\max }$ at high PAR, consequently, have been used by ecophysiologists as an indication of photoinhibition in a wide variety of studies (Falkowski et al. 1994). While photoinhibition has been found in many photosynthetic organisms, curiously, it has rarely been seen in the many studies of the photosynthetic activity of symbiotic dinoflagellates within the tissues of cnidarians (Long et al. 1994, but see Shick et al. 1996 for a rare exception). Photoinhibition at high PAR, for example, was noted for symbiotic dinoflagellates isolated from the sea anemone Aiptasia pulchella, but not for the symbiotic dinoflagellates when studied within the tissues of the host (Muller-Parker 1984). A similar example is noted by Goiran et al. (1996) for the symbiotic dinoflagellate coral Galaxea fascicularis. Other studies of the photoynthetic response curves of symbiotic cnidarians mostly lack the otherwise characteristic decrease in $P_{\max }$ at the highest PAR (Falkowski \& Dubinsky 1980, Wyman et al. 1987. Chalker et al. 1988, Hoegh-Guldberg \& Smith 1989a,b, Davies 1991, Harland \& Davies 1995). The apparent absence of chronic photoinhibition during experiments with symbiotic cnidarians has provoked suggestions that the specialised environment within the cells of symbiotic dinoflagellates and their symbiotic cnidarians might act to reduce or eliminate photoinhibition (Downton et al. 1976, Long et al. 1994). In this regard, the high concentrations of active oxygen scavenging systems (superoxide dismutase, SOD; catalase, CAT; ascorbate oxidase, ASPX) in symbiotic dinoflagellates and the surrounding host tissues are particularly provocative (Lesser 1996).

This paper investigates photoinhibition and associated phenomena in symbiotic dinoflagellates from 2 species of reef-building coral. By using the techniques of pulse-amplitude-modulation (PAM) fluorometry and oxygen respirometry, we have been able to clearly demonstrate that photoinhibition occurs at relatively modest light levels, and is a prominent and normal characteristic of the photosynthetic processes of the symbiotic dinoflagellates in these corals. We also report variations in key photoprotective processes in symbiotic dinoflagellates which indicate that the photosynthetic activity is far more dynamic in symbio than has been previously thought.

\section{MATERIALS AND METHODS}

Collection and maintenance of corals. This research was conducted on expeditions to One Tree Island ( $23^{\circ} 30^{\prime} \mathrm{S}, 152^{\circ} 06^{\prime} \mathrm{E}$; Great Barrier Reef, Australia) in 
March and June 1997, and involved experiments on the reef-building corals Porites cylindrica and Stylophora pistillata, including both the 'brown' and 'pink' colour morphs of the latter (pink colour morphs contain high quantities of the animal pigment pocilloporin, Dove et al. 1995). All corals were collected or studied from a uniform depth of 30 to $40 \mathrm{~cm}$ (mean low water). Corals were either studied in situ on reefs immediately adjacent to the One Tree Island Research Station (OTIRS), or were brought back to the research station and maintained in a flow-through aquarium system. In the latter case, single finger-like branches (4 to $8 \mathrm{~cm}$ in length) were removed from mature coral colonies growing at the top of the inner reef slope of the One Tree Island lagoon. The corals were immediately transported to the laboratory where they were mounted into small plastic racks using non-toxic plastic modelling clay. Generally, corals were left to recover for 2 to $3 \mathrm{~d}$ in the flow-through aquarium prior to use in the experiments.

Measurements of the quantum yield of PSII. The changes in the fluorescence characteristics of symbiotic dinoflagellates in Porites cylindrica and Stylophora pistillata were followed in 2 experiments that involved measurements over the diel cycle. The basic parameters of chlorophyll a fluorescence associated with PSII were measured in colonies of $P$. cylindrica at various intervals over $36 \mathrm{~h}$ in the field (sampling times: 08:00-09:00 h, 14:00-15:00 h, 18:00-19:00 h, 01:0002:00 h) during the first experiment, done over $2 \mathrm{~d}$ in early March 1997 (late austral summer). Replicate, but still attached, sections of each colony ( 3 to 5 replicate colonies per sample time; different colonies were used at each measurement time) were wrapped in foil to exclude light for 30 min to dark-adapt them prior to measurement. The minimal $\left(F_{0}\right)$ and maximal $\left(F_{\mathrm{m}}\right)$ fluorescence yields were measured using a PAM chlorophyll fluorometer (DIVING-PAM, Walz, Germany; see Schreiber et al. 1997 for specifications). A weak pulsed red light $\left(<1 \mu \mathrm{mol}\right.$ quanta $\left.\mathrm{m}^{-2} \mathrm{~s}^{-1}\right)$ was given to determine $F_{0}$ in a dark-adapted state or $F$ in an illuminated state. A saturating pulse (intensity $>4000 \mu \mathrm{mol} \mathrm{m} \mathrm{m}^{-2} \mathrm{~s}^{-1}$ PAR for $800 \mathrm{~ms}$ ) was applied to determine $F_{\mathrm{m}}$ (in a dark-adapted state) or $F_{\mathrm{m}}{ }^{\prime}$ (in an illuminated coral). The change in fluorescence $(\Delta F)$ caused by the saturating pulse in relation to the maximal fluorescence yield ( $F_{\mathrm{m}}$ or $F_{\mathrm{m}}$ ') has been shown to be a good measure of quantum yield (Genty et al. 1989). Thus $\Delta F / F_{\mathrm{m}}$ (dark-adapted) $=F_{v} / F_{m}=$ maximum potential quantum yield, and $\Delta F / F_{\mathrm{m}}$ ' (illuminated sample) = maximum effective quantum yield. To examine the length of the dark-adaptation period required to accurately determine $F_{\mathrm{v}} / F_{\mathrm{m}}$ in corals, 24 fragments (branches) of $S$. pistillata (brown colour morphs) were exposed to full sunlight ( $>1000 \mu \mathrm{mol}$ quanta $\mathrm{m}^{-2} \mathrm{~s}^{-1}$ ) for $2 \mathrm{~h}$. Corals were then placed in darkness and $F_{\mathrm{v}} / F_{\mathrm{m}}$ determined in 3 fragments at $1,2.5,5,10,20$ and 40 min intervals.

$\triangle F / F_{\mathrm{m}}$ were measured for the same corals after incubating them for $1 \mathrm{~min}$ at each of a series of 8 irradiances that increased in steps from 120 to $2340 \mu \mathrm{mol}$ $\mathrm{m}^{-2} \mathrm{~s}^{-1}$ PAR. $F$ and $F_{\mathrm{m}}$ ' were measured at the end of each 1 min illumination period. $\Delta F / F_{\mathrm{m}}\left(Y^{\prime}\right)$ from this experiment were used to calculate apparent relative electron transport rates (ETR). This calculation was based on the incubation irradiance (photon flux density, PFD) and the assumption that half the photons required for the movement of electrons through the photosystems of symbiotic dinoflagellates are absorbed by PSII (Schreiber et al. 1994; ETR $=Y^{\prime} \times \mathrm{PFD} \times$ $0.5)$. The validity of this calculation for symbiotic dinoflagellates is supported by other research that shows that calculated ETR values are approximately linear with photosynthetic rates measured simultaneously from oxygen flux measurements made with a respirometer (Hoegh-Guldberg \& Jones unpubl.). ETR data was plotted against incubation irradiance to provide light response curves for Porites cylindrica as a function of time of day.

The experiment was repeated during the June 1997 expedition (austral winter) using both Porites cylindrica and Stylophora pistillata. In this case, the experiment was done on corals housed in the flow-through seawater system at OTIRS under natural irradiances. The chlorophyll fluorescence characteristics were measured at each time point on 4 pieces of $P$. cylindrica and brown and pink colour morphs of $S$. pistillata. Irradiance levels in this experiment were monitored every 15 min using a LICOR LI-189 photometer with a LI190SA quantum sensor. Temperature was measured using a mercury bulb thermometer. Measurements were done hourly from pre-dawn to midnight over 3 day-night cycles and included the dark-acclimation of corals for $30 \mathrm{~min}$ prior to measuring $F_{0}$ and $F_{\mathrm{m}}$ as described above. In this experiment, a separate set of corals of each species/colour morph was used to measure $\Delta F / F_{m}$ at different irradiance as a function of time of day. These measurements were done over the last 2 diel cycles of this experiment.

Quenching analysis. The quenching of chlorophyll a fluorescence by symbiotic dinoflagellates in Porites cylindrica and Stylophora pistillata was analysed as a function of time of day. Four corals of $P$. cylindrica and of each colour morph of $S$. pistillata were sampled at 06:00 $\mathrm{h}$ prior to sunrise, and at 14:00 h, following the solar zenith. Corals were dark-adapted for $30 \mathrm{~min}$ prior to being mounted over the optical cone of a TEACHING-PAM chlorophyll fluorometer (Walz, Germany; see Schreiber et al. 1997 for specifications). The specimen was kept wet during these measurements with a few drops of seawater between the surface of the spec- 

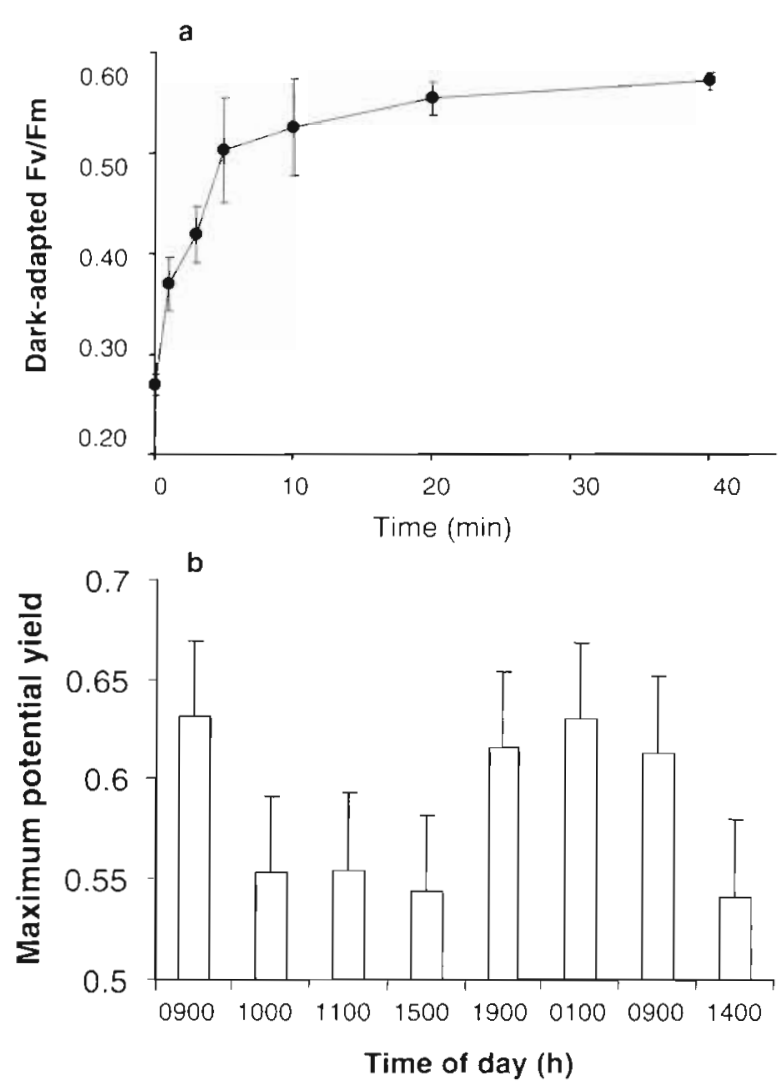

Fig. 1. (a) Changes in $F_{v} / F_{m}$ in symbiotic dinoflagellates of Stylophora pistillata (brown morphs) exposed to $>1000 \mu \mathrm{mol}$ quanta $\mathrm{m}^{-2} \mathrm{~s}^{-1}$ for $2 \mathrm{~h}$ during the middle of the day and then placed in darkness for different intervals ( $X$-axis) prior to measurement. Data are means $\pm \mathrm{SE}, \mathrm{n}=3$ independent replicates at each time point. (b) Dark-adapted $F_{\mathrm{v}} / F_{\mathrm{m}}$ of symbiotic dinoflagellates measured within the tissues of Porites cylindrica in early March 1997 on reefs at One Tree Island $\left(23^{\circ} 30^{\prime} \mathrm{S}, 152^{\circ} 06^{\prime} \mathrm{E}\right)$. Specimens were dark-adapted for 30 min prior to each measurement. Data are means \pm SE

imen and the optical cone of the fluorometer (Schreiber et al. 1997). The quenching characteristics of the symbiotic dinoflagellates in each coral was investigated during each incubation in response to actinic light of $800 \mu \mathrm{mol} \mathrm{m} \mathrm{m}^{-2} \mathrm{~s}^{-1} \mathrm{PAR}$. Photochemical [ $\mathrm{qP}=$ $\left.\left(F_{\mathrm{m}}{ }^{\prime}-F\right) /\left(F_{\mathrm{m}}{ }^{\prime}-F_{0}{ }^{\prime}\right)\right]$ and non-photochemical [NPQ = $\left.\left(F_{\mathrm{m}}-F_{\mathrm{m}}{ }^{\prime}\right) / F_{\mathrm{m}}{ }^{\prime}\right]$ quenching components were calculated in addition to maximum $F_{\mathrm{v}} / F_{\mathrm{m}}$, maximum $\Delta F / F_{\mathrm{m},} F_{\mathrm{m}}$ $F_{0}$ and $F_{\mathrm{m}}$ ', which were measured during each experimental run (Schreiber \& Bilger 1987). $F_{0}$ (observed as a downward drift in $F$ ) was observed to undergo slow but significant quenching (downward drift) in symbiotic dinoflagellates sampled prior to dawn. qP was calculated using $F_{0}$ corrected for the downward drift $\left[F_{0}^{\prime}=F_{0} \times F(0) / F(n)\right.$, where $F(0)$ is $F$ at the beginning of the light period, and $F(n)$ is the value of $F$ at time $=n$ ].

Respirometry. Photosynthetic and respiratory rates were measured using a respirometer that consisted of 4 separate $90 \mathrm{ml}$ acrylic chambers enclosed in a recir- culating water jacket. Corals were placed within each chamber over a perforated floor, underneath which was a stir-bar powered by a magnetic stirrer Two $50 \mathrm{~W}$ quartz-halogen lights illuminated each chamber from opposite sides. Changes in the concentration of oxygen within the chambers were measured using Clark-type polarographic oxygen electrodes (Strathkelvin Instruments, Glasgow, UK) that were inserted into the top of each chamber. The oxygen sensors were connected via polarising units to an analogue-to-digital converter (ADC-1, Remote Measurement Systems, Seattle, USA) and an IBM-compatible 486-laptop computer running data acquisition software (Sable Systems, Los Angeles, USA). Oxygen concentrations were measured every $20 \mathrm{~s}$ from an average of 2 consecutive voltage readings from each sensor. The voltage responses of the sensors were calibrated using air-saturated seawater at the incubation temperature and salinity, and oxygen purged (nitrogen bubbled) seawater (34\% salinity). Software (Temptabl, Oxford University Press, 1986) was used to calculate the oxygen concentrations at saturation for each experimental temperature and salinity. Photosynthetic rates (at $750 \mu \mathrm{mol} \mathrm{m} \mathrm{m}^{-2} \mathrm{~s}^{-1} \mathrm{PAR}$ for $20 \mathrm{~min}$ ) and then respiratory rates (in dark for $30 \mathrm{~min}$ ) were measured for 4 corals at each time point. Following each dark measurement, $F_{\mathrm{v}} / F_{\mathrm{m}}$ were measured as described above. The corals were then frozen and taken back to the University of Sydney, where the number of symbiotic dinoflagellates and surface area were measured. This was done by stripping the tissues off the underlying skeleton using a jet of recirculated seawater (Johannes \& Wiebe 1970) and measuring the density of symbiotic dinoflagellates in the resulting homogenate using a hemacytometer ( 8 separate chamber counts).

\section{RESULTS}

\section{Changes in $F_{0}, F_{\mathrm{m}}$ and dark-adapted $F_{\mathrm{v}} / F_{\mathrm{m}}$}

$F_{\mathrm{v}} / F_{\mathrm{m}}$ of the symbiotic dinoflagellates in fragments of Stylophora pistillata (brown colour morphs) exposed to $>1000 \mu \mathrm{mol}$ quanta $\mathrm{m}^{-2} \mathrm{~s}^{-1}$ for $2 \mathrm{~h}$ during the middle of the day increased rapidly as a function of the length of time in darkness (dark-adapted Fig. 1a). Most change in dark-adapted $F_{\mathrm{v}} / F_{\mathrm{m}}$ occurred in the first 5 to $10 \mathrm{~min}$ of dark-adaptation, after which there was little change. Accordingly, a $30 \mathrm{~min}$ period of dark-adaptation was considered suitable for subsequent measurements of dark-adapted $F_{\mathrm{v}} / F_{\mathrm{m}}$. The dark-adapted $F_{\mathrm{v}} / F_{\mathrm{m} 2}$ of symbiotic dinoflagellates in Porites cylindrica and both colour morphs of $S$. pistillata showed distinct changes over the course of the day during both experiments (Figs. 1b \& 2a,b). During the June 1997 study, dark- 


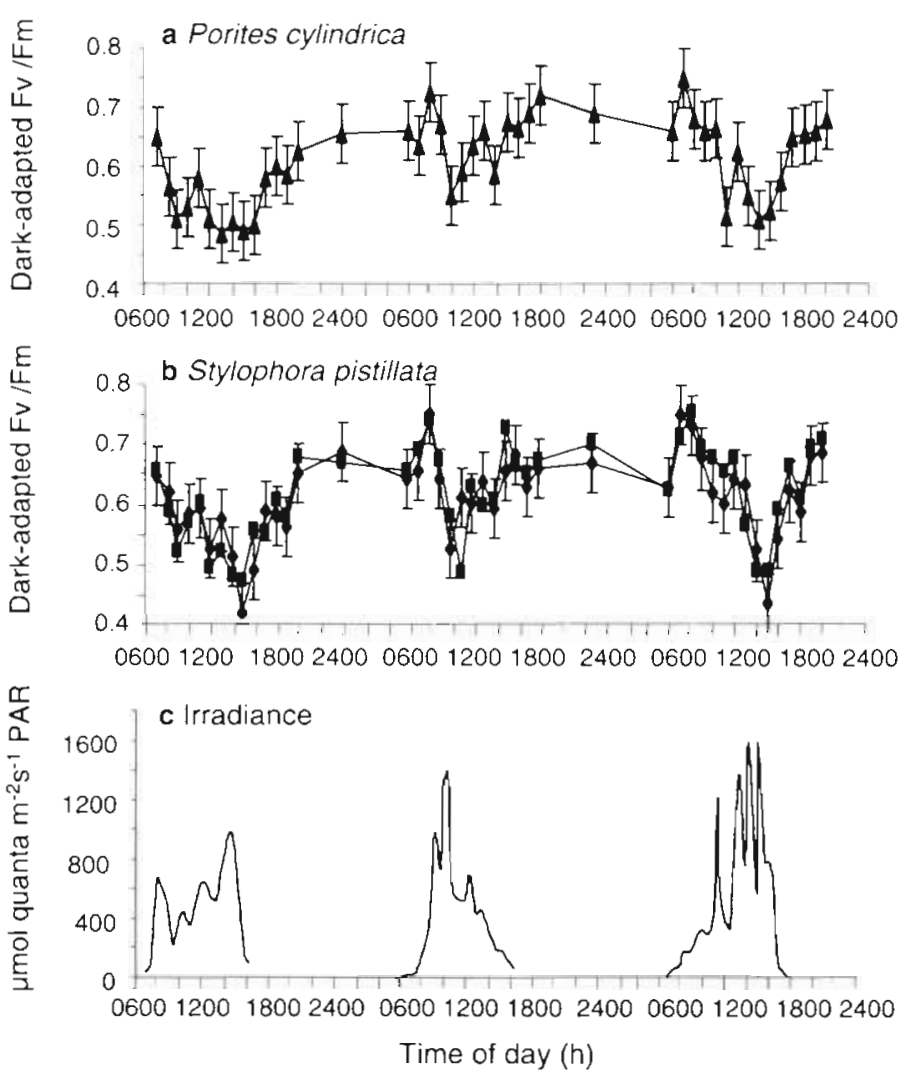

Fig. 2. Dark-adapted $F_{\mathrm{v}} / F_{\mathrm{t}}$ of symbiotic dinoflagellates measured within the tissues of (a) Porites cylindrica and (b) Stylophora pistillata $(*$ pink colour morphs, $\mathbf{\square}=$ brown colour morphs) over the course of $3 \mathrm{~d}$ at One Tree Island in June 1997 Specimens were dark-adapted for 30 min before measurement. Data are means $\pm \mathrm{SE}$ for 4 colonies of $P$. cylindrica and 4 colonies of each colour morph of $S$. pistillata. (c) Light levels (PAR) were measured beside colonies. Temperatures within the experiments were: Day $1=22 \pm 1.0^{\circ} \mathrm{C}$ (mean $\pm \mathrm{SD}$ ), Day $2=22.3 \pm 1.0^{\circ} \mathrm{C}$, Day $3=21.1 \pm 0.5^{\circ} \mathrm{C}$

adapted $F_{\mathrm{v}} / F_{\mathrm{m}}$ dropped from 0.65 in both species to less than 0.5 by $12: 00 \mathrm{~h}$ on the first day. Dark-adapted $F_{\mathrm{v}} / F_{\mathrm{m}}$ generally decreased as light levels increased occurring on each day and the lowest values coincided with the highest irradiances (Fig. 2a to c). Darkadapted $F_{\mathrm{v}} / F_{\mathrm{m}}$ began to increase again as light levels began to decrease in the early afternoon, and had returned to their pre-dawn values by approximately 20:00 h each evening. Water temperatures within the experiment did not vary by much over the 3 days (mean $\pm \mathrm{SD}$ : Day $1=22 \pm 1.0^{\circ} \mathrm{C}$, Day $2=22.3 \pm 1.0^{\circ} \mathrm{C}$, Day $3=21.1 \pm 0.5^{\circ} \mathrm{C}$ ). Interestingly, dark-adapted $F_{\mathrm{v}} / F_{\mathrm{m}}$ increased to 0.7 in both species just after dawn (between 07:00 and 08:00 h) on the second and third days. This coincided with light levels that were between 20 and $100 \mu \mathrm{mol} \mathrm{m} \mathrm{m}^{-2} \mathrm{~s}^{-1}$ PAR. They had dropped to 0.65 again by $09: 00 \mathrm{~h}$, when light levels were generaliy above $300 \mu \mathrm{mol} \mathrm{m} \mathrm{m}^{-2} \mathrm{~s}^{-1}$ PAR.
$F_{0}$ and $F_{\mathrm{m}}$, used to calculate dark-adapted $F_{\mathrm{v}} / F_{\mathrm{m}}$ changed as a function of light level during the diel cycle (Fig. 3 a,b; June 1997). Both $F_{0}$ and $F_{m}$ decreased with increasing light levels and slowly returned to their pre-dawn values by approximately 20:00 h. Changes in $F_{0}$ were slightly less marked (decreasing to $60 \%$ of pre-dawn values on the first day) than changes in $F_{\mathrm{m}}$ (decreasing to $40 \%$ of pre-dawn values during the first day). $F_{0}$ also showed some tendency to drift downward during the course of the experiment, especially during the first 2 days.

\section{Quenching analysis}

Chlorophyll fluorescence quenching analysis was used to investigate regulatory phenomena associated with symbiotic dinoflagellates that were exposed to
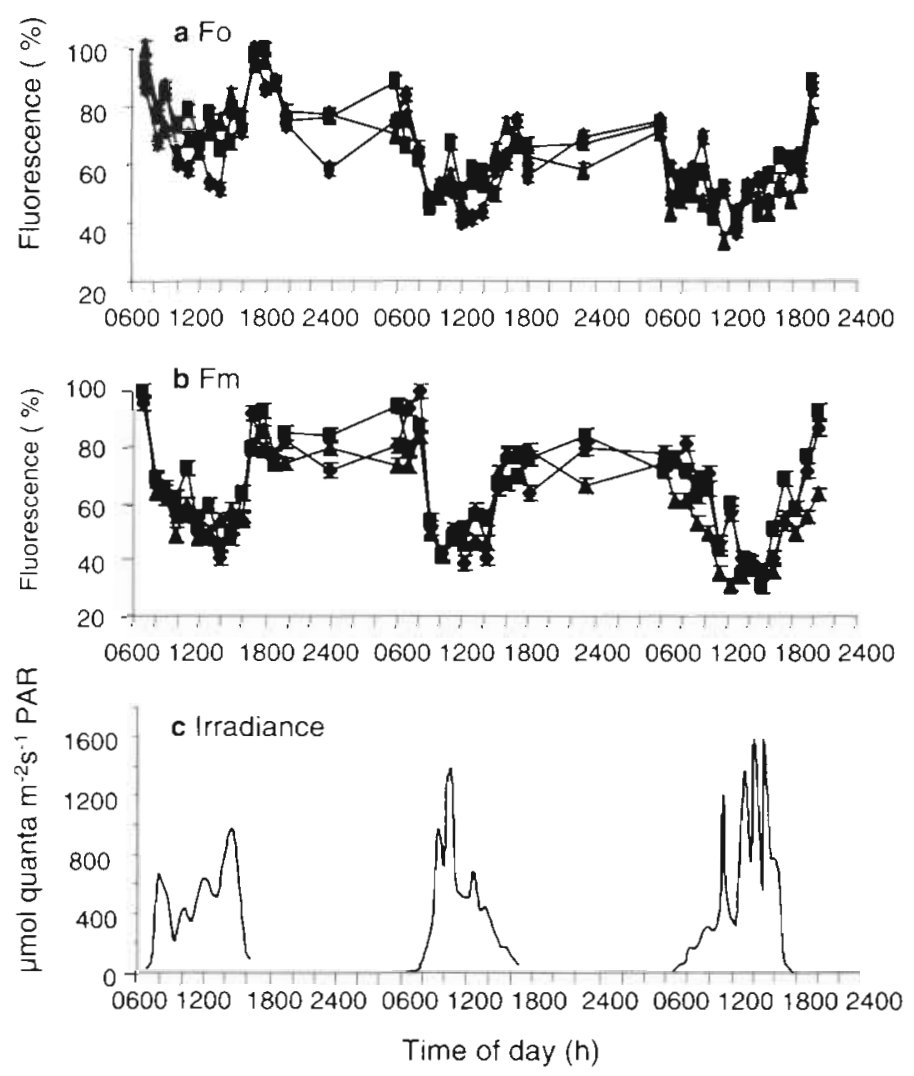

Fig. 3. (a) Minimal fluorescence yields $\left(F_{0}\right)$ and (b) maximal fluorescence yields $\left(F_{\mathrm{m}}\right)$ of symbiotic dinoflagellates in Porites cylindrica (4) and Stylophora pistillata $(\bullet=$ pink colour morphs, $\boldsymbol{\omega}=$ brown colour morphs) measured over $3 \mathrm{~d}$ at One Tree Island in June 1997. Colonies were dark-adapted for $30 \mathrm{~min}$ before measurement. Data are means \pm SE for 4 colonies of $P$. cylindrica and 4 colonies of each colour morph of S. pistillata. (c) Light levels (PAR) measured beside colonies. Temperatures within the experiments were: Day $1=22 \pm 1.0^{\circ} \mathrm{C}$ $($ mean $\pm \mathrm{SD})$, Day $2=22.3 \pm 1.0^{\circ} \mathrm{C}$, Day $3=21.1 \pm 0.5^{\circ} \mathrm{C}$ 

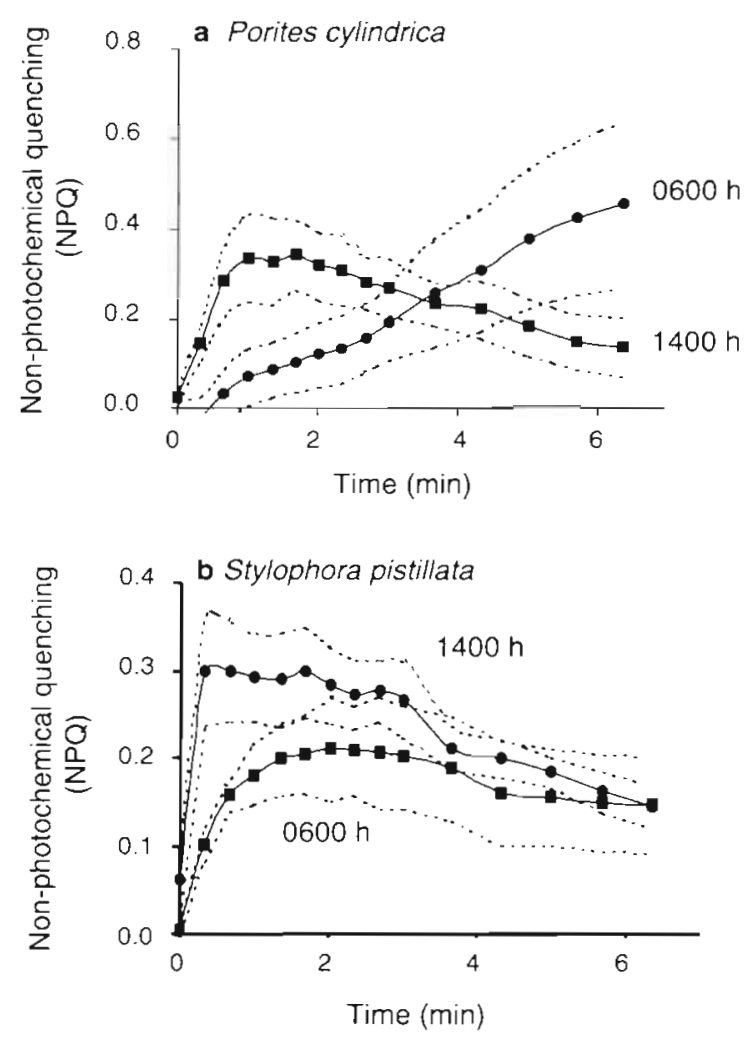

Fig. 4. Comparison of quenching responses (non-photochemical quenching [NPQ] of photosystem II) of symbiotic dinoflagellates in (a) Porites cylindrica and (b) the brown colour morphs of Stylophora pistillata as a function of time of day in June 1997. Four corals of each species were sampled at 06:00 $\mathrm{h}$ (prior to sunrise) and 14:00 $\mathrm{h}$ (following the solar zenith). Shown are means $(n=4)$ and $95 \%$ confidence limits (dashed lines)

light for different lengths of time. This procedure allows the identification of specific control mechanisms that underlie changes in quantum efficiency. Symbiotic dinoflagellates in corals that were measured prior to sunrise had distinctly different quenching characteristics to those that had been exposed to light for an extended period over the day (compare 06:00 $\mathrm{h}$ with 14:00 h measurements, Fig. $4 a, b_{i} p<0.05$ ). Symbiotic dinoflagellates from corals that had been exposed to natural irradiances from sunrise until the early afternoon showed a classic pattern of regulation of energy flux through PSII via NPQ (compare Fig. 4a, 14:00 h measurement with Fig. 9a of Schreiber \& Bilger 1987, p. 40). Symbiotic dinoflagellates from pre-dawn corals, however, had reduced abilities to rapidly quench PSII using NPQ (Fig. 4a,b). This is shown most dramatically in Porites cylindrica, which showed rapid induction of NPQ in the early afternoon, but showed a much slower induction of the same phenomenon in the symbiotic dinoflagellates in corals sampled prior to dawn (Fig. 4a).
Symbiotic dinoflagellates from the 2 corals sampled pre-dawn versus in the early afternoon also showed other differences in dynamics of the fluorescent transient following induction by modest light levels. Perhaps the most interesting of these was the tendency for dark fluorescence $\left(F_{;}\right.$an approximation of $\left.F_{0}{ }^{\prime}\right)$ to remain well above $F_{0}$ (measured just before the end of the dark period) for longer in the pre-dawn samples. The differences were quite marked, with $F$ remaining above $F_{0}$ for at least $6 \mathrm{~min}$ in the pre-dawn corals while dropping to $F_{0}$ within a few seconds in symbiotic dinoflagellates from corals sampled in the early afternoon (Fig. 5a,b). Trends were strongest for Porites cylindrica, yet were still significant $(p<0.05)$ though less pronounced in Stylophora pistillata.

Regulatory phenomena and the ease of electron flow beyond PSII (e.g. activation of Calvin-Benson cycle enzymes) ultimately determine the quenching of excitations in PSIl by the photochemistry of the symbiotic dinoflagellates. $\mathrm{qP}$ is a measure of the average oxida-
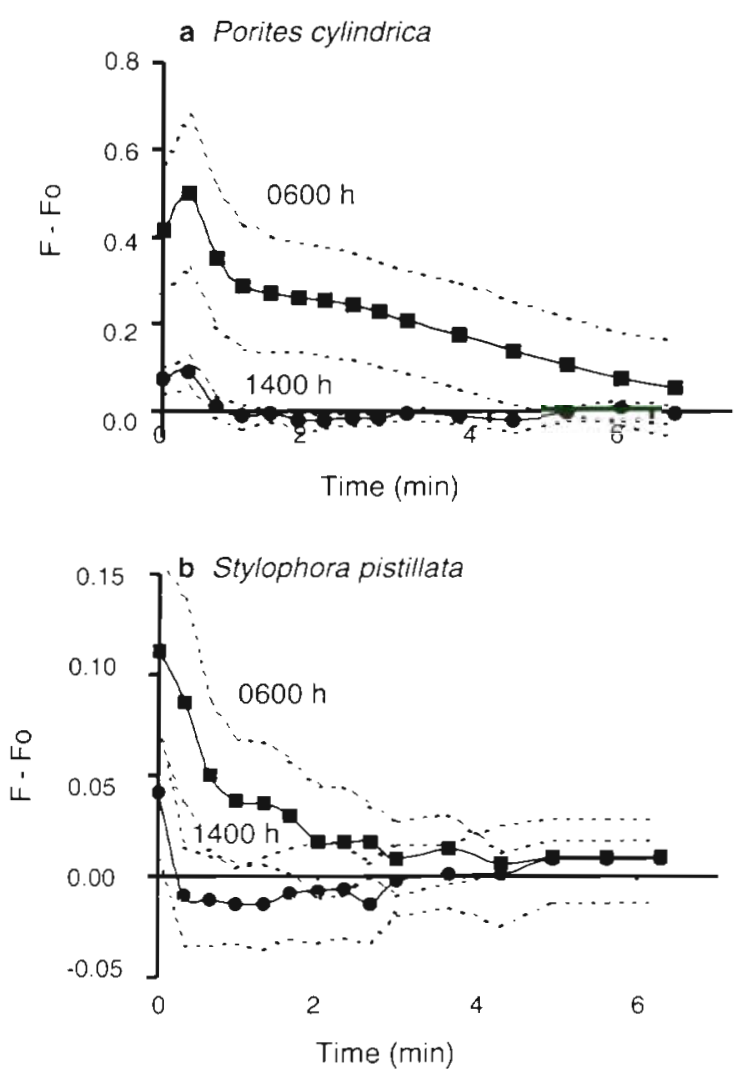

Fig. 5. Comparison of quenching responses (difference between $F$ and $F_{0}$ ) of symbiotic dinoflagellates in (a) Porites cylindrica and (b) the brown colour morphs of Stylophora pistillata as a function of time of day in June 1997 . Four corals of each species were sampled at 06:00 h (prior to sunrise) and 14:00 h (following the solar zenith). Shown are means $(n=4)$ and $95 \%$ confidence limits (dashed lines) 

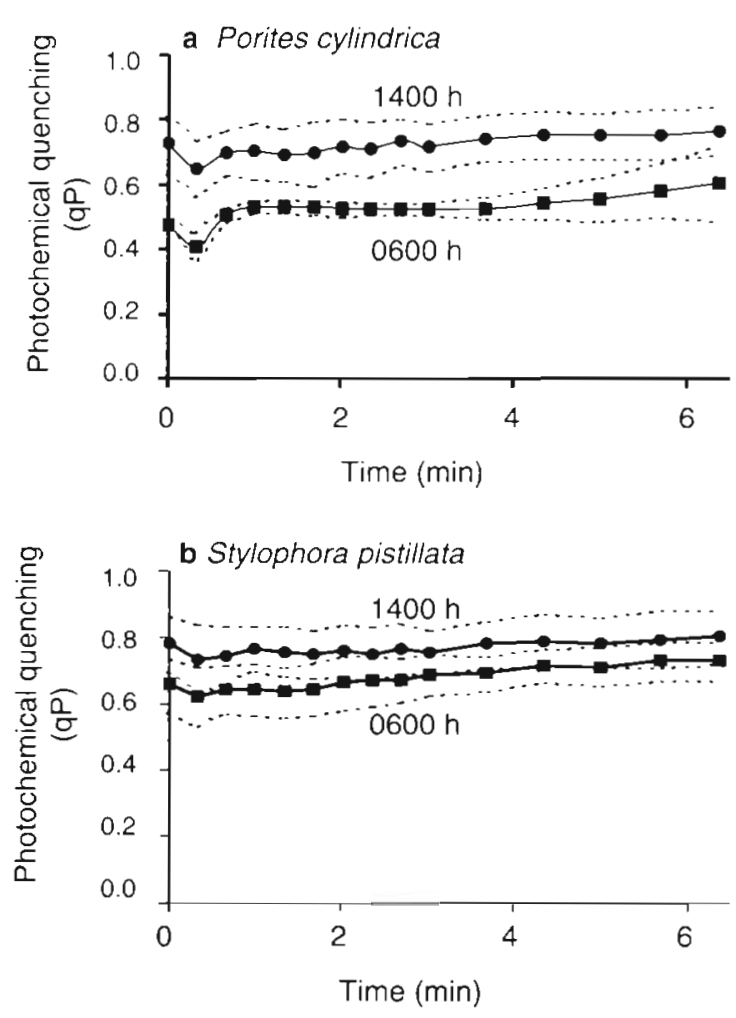

Fig. 6. Comparison of quenching responses (photochemical quenching (qP]) of symbiotic dinoflagellates in (a) Porites cylindrica and (b) the brown colour morphs of Stylophora pistillata at One Tree Island as a function of time of day in June 1997. Four corals of each species were sampled at 06:00 $\mathrm{h}$ (prior to sunrise) and 14:00 $\mathrm{h}$ (following the solar zenith). Shown are means ( $n=4)$ and $95 \%$ confidence limits (dashed lines)

tion state of the primary acceptor pool, $Q_{A}$. The greater the value of $\mathrm{qP}$, the higher the throughput of energy to acceptors downstream of this redox pool. $q P$ was higher $(p<0.05)$ initially in symbiotic dinoflagellates from light-acclimated (i.e. early afternoon) colonies of both coral species (Fig. 6a,b). Notably, after 6 min of PAR irradiation, the $\mathrm{qP}$ of symbiotic dinoflagellates from pre-dawn and early afternoon corals were no longer statistically different.

\section{Electron transport rate and maximum effective yields at saturation and as a function of time of day}

Light response curves (ETR vs irradiance) showed a consistent pattern of change over the course of the day for both species. In all cases, the capacity of symbiotic dinoflagellates for electron transport increased from sunrise to midday and then decreased gradually to sunset (Fig. 7a,b). These changes in ETR are under-

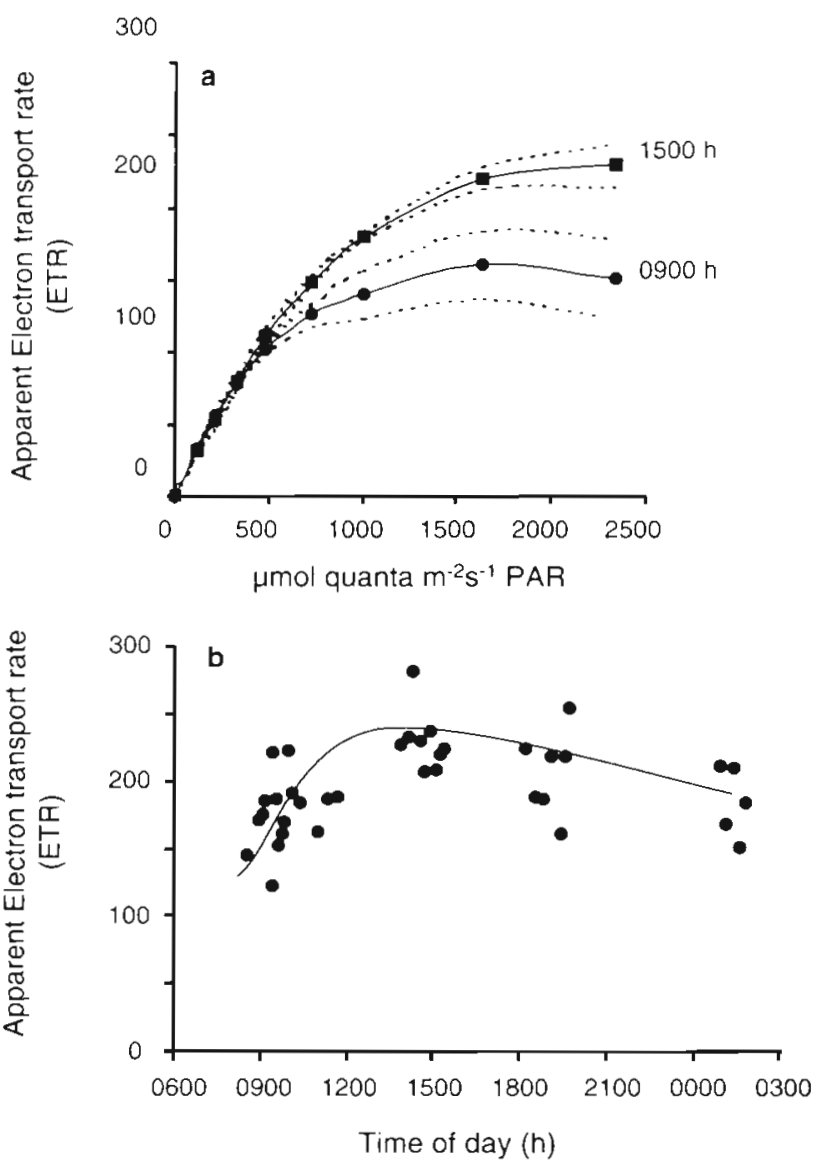

Fig. 7. Electron transport rates (ETR) of symbiotic dinoflagellates in Porites cylindrica measured in the field at One Tree Island in March 1997 (a) Apparent ETR as a function of irradiance at 09:00 h and at 15:00 h. Shown are means $(n=4)$ and 95\% confidence limits (dashed lines). (b) Apparent ETR at light saturation as a function of time of day. Shown are the means of duplicate measurements from individual colonies. Trends are indicated by line of best fit

pinned by changes in $\Delta F / F_{\mathrm{m}} . \Delta F / F_{\mathrm{m}}$ after exposure to a series of light intensities (culminating in $1555 \mu \mathrm{mol}$ $\mathrm{m}^{-2} \mathrm{~s}^{-1}$ PAR increased from dawn [06:00 h] to values that are almost 2-fold higher by about 09:00 $\mathrm{h}$ (Fig. 8a,b; both species, winter).

\section{Oxygen flux measurements}

The gross rate of photosynthesis $\left(P_{\mathrm{g}}\right)$ per dinoflagellate cell (range 1.1 to $1.8 \mathrm{pg} \mathrm{O}_{2} \mathrm{cell}^{-1} \mathrm{~h}^{-1}$ ) in colour morphs of Stylophora pistillata did not vary as a function of time of day (Fig. 9a). Dark-adapted $F_{\mathrm{v}} / F_{\mathrm{m}}$ measured at the same time showed the characteristic variation with light level seen previously in this study (Fig. 9b; see also Fig. 2b). 

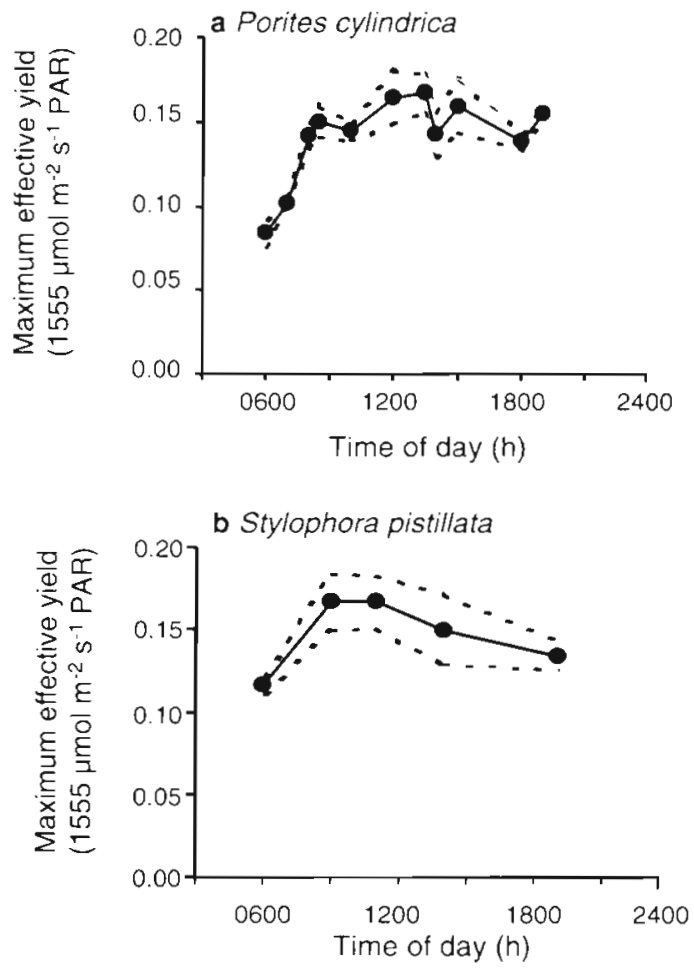

Fig. 8. Maximum effective yields $\left(\Delta F / F_{\mathrm{m}}\right)$ at the end of a series of eight $1 \mathrm{~min}$ irradiances that increased and culminated in 1 min of irradiation at PAR of $1555 \mu \mathrm{mol}$ photon $\mathrm{m}^{-2} \mathrm{~s}^{-1}$ for symbiotic dinoflagellates from (a) Porites cylindrica and (b) the brown colour morphs of Stylophora pistillata as a function of time of day at One Tree Island in June 1997. Shown are means $(n=4)$ and $95 \%$ confidence limits (dashed lines)

\section{DISCUSSION}

The results of this study clearly show that symbiotic dinoflagellates experience photoinhibition in symbio, and are similar to other marine plants that have been examined (Falkowski et al. 1994, Franklin et al. 1996). Our studies also highlight the dynamic nature of the photosynthetic machinery of symbiotic dinoflagellates of corals and indicate that photoinhibitory modifications of the quantum efficiency occur even on winter days for corals growing on a high latitude reefs.

\section{Photoinhibition in symbiotic dinoflagellates}

Photoinhibition is defined as any decrease in the capacity of a photosystem to capture and process photons that is caused by incoming light (Long et al. 1994. Osmond 1994). In studies of PSII chlorophyll fluorescence this is synonymous with light-related decreases in the dark-adapted $F_{\mathrm{v}} / F_{\mathrm{m}}$, a measure of the maximum potential quantum yield in plants (Schreiber \& Bilger
1987, Falkowski et al. 1994). In Porites cylindrica and the 2 colour morphs of Stylophora pistillata, relatively minor PAR fluxes (200 to $400 \mu \mathrm{mol} \mathrm{m} \mathrm{m}^{-2} \mathrm{~s}^{-1} \mathrm{PAR}$ ) resulted in significant reductions $(\mathrm{p}<0.01)$ in darkadapted $F_{\mathrm{v}} / F_{\mathrm{m}}$ (Figs. $1 \& 2$ ). The lowest values of darkadapted $F_{v} / F_{m}$ occurred during the highest light levels and trends were identical in both coral species. Consequently, the symbiotic dinoflagellates in the 2 species of reef-building coral studied here clearly exhibited photoinhibition.

The quantity of incoming PAR had a large influence on dark-adapted $F_{v} / F_{m}$ on the second and third days of the study (Fig. 2). Light levels on the second day were strongest in the morning and were reduced by cloud during the afternoon. Dark-adapted $F_{v} / F_{\mathrm{m}}$ in this case dropped quickly to approximately 0.5 by midday and then rose slowly back to 0.65 a few hours after light levels had decreased in the early afternoon. Opposite trends were evident for the third day. In this case, clouds reduced light levels in the morning and the normal decrease in dark-adapted $F_{\mathrm{v}} / F_{\mathrm{m}}$ began later, but
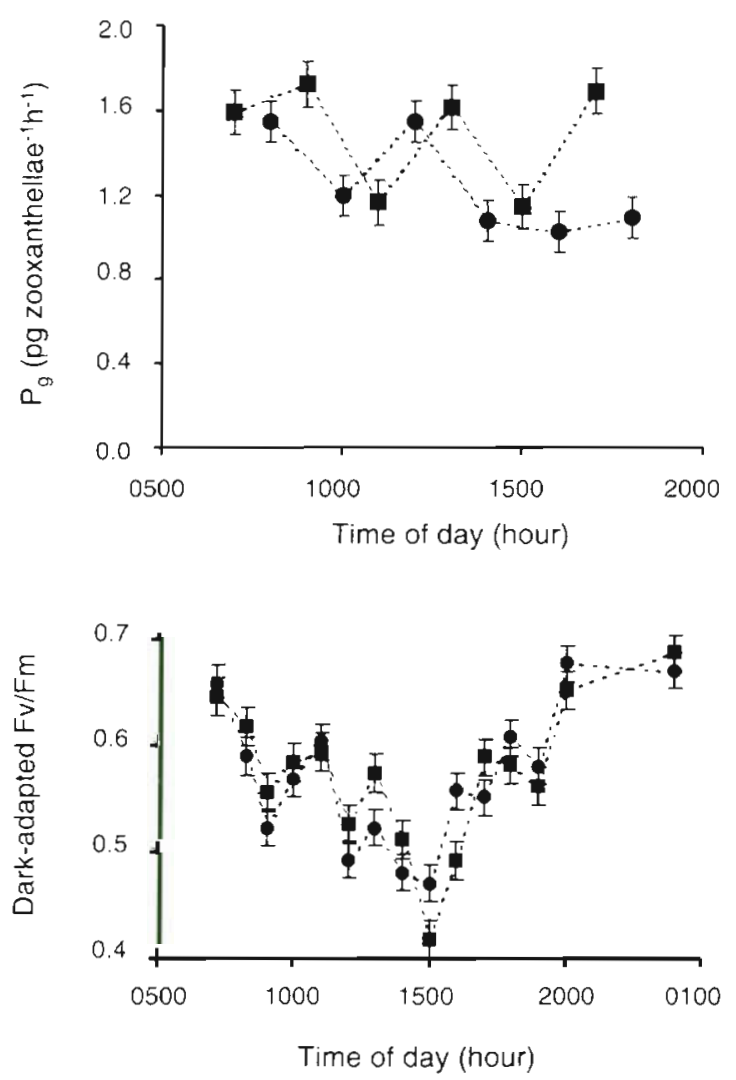

Fig. 9. (a) Gross photosynthetic rates of colonies of the browm (-) and pink (-) morphs of Stylophora pistillata as a function of time of day. (b) Maximum potential quantum yield $\left(F_{v} / F_{\mathrm{m}}\right)$ of the same colonies. Specimens were dark acclimated for 30 min prior to each measurement. Data are means \pm SE for 4 colonies of each morph 
eventually reached a value in the early afternoon that was similar to that seen earlier on the first day. Similar changes have been seen for higher plants (e.g. Cheeseman et al. 1997), macroalgae (Henley et al. 1992, Hanelt et al. 1993) and other microalgae (Falkowski et al. 1994, Vassiliev et al. 1994). It is notable that the changes in dark-adapted $F_{\mathrm{v}} / F_{\mathrm{m}}$ reported here for symbiotic dinoflagellates in corals occurred under the low light conditions of a cloudy winter day on a high latitude $\left(23^{\circ} 30^{\prime} \mathrm{S}\right)$ coral reef.

Changes in dark-adapted $F_{\mathrm{v}} / F_{\mathrm{m}}$ reflect the energy conversion efficiency or capacity of PSII to process captured light photochemically (Schreiber \& Bilger 1987, Long et al. 1994, Schreiber et al. 1996) and are due to changes in the composition and organisation of the light harvesting complex associated with PSII (Demmig-Adams et al. 1989, Krause \& Weis 1991, Walker 1992, Horton \& Ruban 1994, Long et al. 1994, Bukhov et al. 1996, Young \& Frank 1996). Almost identical responses in dark-adapted $F_{\mathrm{v}} / F_{\mathrm{m}}, F_{\mathrm{m}}$ and $F_{0}$ for symbiotic dinoflagellates in corals at One Tree Island have been reported for macroalgae at the same location and time of year (Franklin et al. 1996). In this case, decreases in dark-adapted $F_{v} / F_{\mathrm{m}}$ and $F_{0}$ were shown to be correlated with the conversion of violaxanthin into zeaxanthin by the enzyme violaxanthin epoxidase. These 2 carotenoids were prominent in the xanthophyll cycle of most of the macroalgae studied by Franklin et al. (1996). An increased ratio of zeaxanthin to violaxanthin is thought to increase the rate of thermal dissipation away from PSII, thereby decreasing the amount of energy flowing towards the reaction centre (Demmig-Adams et al. 1989, for review, see Young \& Frank 1996). The avoidance of over-reduction of reaction centres and electron transport components reduces the production of active forms of oxygen (Asada \& Takahashi 1987), and thereby reduces the risk of subsequent oxidative damage. Dinoflagellates and diatoms have different but comparable compounds (monoepoxide diadinoxanthin, DD, and diatoxanthin, DT) which appear to serve the same roles as violaxanthin and zeaxanthin and within the light harvesting structures of these organisms (Olaizola \& Yamamoto 1994, Olaizola et al. 1994, Young \& Frank 1996, Rhiel et al. 1997). The decreases in $F_{0}$ during the present study are also indicative that the de-epoxidation of xanthophyll pigments like DD are involved in increasing the thermal dissipation of energy away from PSII. $F_{0}$ is a measure of the initial energy distribution within PSII and of the efficiency of energy trapping by P680 (Schreiber \& Bilger 1987). Decreases in $F_{0}$, consequently, indicate that the increased dissipation of energy within the light harvesting antennae are probably associated with the formation of DT as they are strongly correlated with the formation of zeaxan- thin in marine algae (Franklin et al. 1992, 1996). Similar decreases in $F_{0}$ occur as the ratio of DT to DD increases in both diatoms (Arsalane et al. 1994, Olaizola \& Yamamoto 1994) and free-living dinoflagellates (Johnson \& Sakshaug 1993). Changes in the ratio of DT to DD in symbiotic dinoflagellates of the coral Goniastrea aspera have recently been correlated with the light environment of corals growing intertidally in Thailand (Ambarsari et al. 1997). These results further suggest that xanthophyll cycle inter-conversions are likely to be central to the acclimative and adaptive abilities of symbiotic dinoflagellates in the face of high PAR conditions and stresses such as those during thermally related bleaching (Jones et al. 1998).

\section{Variability in quantum efficiency and non-photochemical quenching}

Symbiotic dinoflagellates sampled in the early afternoon (after most of a day of sunlight) were able to more rapidly engage NPQ of PSII excitations when undergoing a transition from dark to light (Fig. 4a, b). The significantly slower decay of the baseline fluorescence $\left(F-F_{0}\right.$, Fig, 5a,b) in the pre-dawn dinoflagellates when exposed to moderately high actinic light $\left(800 \mu \mathrm{mol} \mathrm{m} \mathrm{m}^{-2}\right.$ $\mathrm{s}^{-1}$ PAR) also indicates a much slower induction of energy-dependent quenching. The efficient engagement of NPQ requires a sufficiently large pool of epoxidase (Demmig-Adams et al. 1989). The present study indicates that epoxidase levels are probably depleted (or deactivated) during the night such that the engagement of NPQ was much slower just prior to dawn than in the early afternoon. Similarly, it appears that epoxidase levels increase (or existing epoxidase is reactivated) in symbiotic dinoflagellates as they experience elevated light levels. In concert with changes in the ability to engage NPQ were the expected differences in $\mathrm{qP}$. In this case, symbiotic dinoflagellates sampled prior to light exposure had lower qP than those sampled after most of a day of sunlight (Fig. 6a,b). These differences indicate that a greater proportion of the acceptor pool $\left(Q_{\mathrm{A}}\right)$ was available in symbiotic dinoflagellates that had been exposed to light for some time.

qP indicates the proportion of captured light energy that is used for processes requiring electrons downstream of PSII. By the analysis so far, the prediction is that the transport of electrons beyond PSII would be depressed earlier in the day. This was indeed the case when the rate of apparent ETR was investigated as a function of time of day. Maximum effective yields or ETR for symbiotic dinoflagellates in both Porites cylindrica and Stylophora pistillata measured at light-saturation (>1000 $\mu \mathrm{mol} \mathrm{m} \mathrm{m}^{-2} \mathrm{~s}^{-1}$ PAR) varied significantly $(p<0.05)$ during the course of the diel cycle (Figs. $7 \& 8$ ). 
Just prior to dawn, light-saturated ETR were lower by comparison to later in the day by as much as $50 \%$. Light-saturated ETR increased until maxima occurred in the early afternoon in concert with the declines measured in $F_{v} / F_{\mathrm{m}}$ discussed previously. Rates declined slowly overnight, however, indicating that the processes involved took about $12 \mathrm{~h}$ to recover from light exposure during the day. The increases in the $\Delta F / F_{\mathrm{m}}$ (after exposure to high light levels) during the middle of the day indicate that $Q_{A}$ is less reduced (and electron flow beyond PSII more efficient) for a given photon influx than earlier in the day. There are several possible reasons for the more efficient processing of excitations by symbiotic dinoflagellates during the early afternoon. The first possibility is that light exposure evokes the up-regulation of processes that are related to carbon fixation by Rubisco. Increased enzyme activity could relate to the increased expression or activation-state of existing enzymes, or to changes in their activity caused by local availability of substrates such as carbon dioxide. Changes in the availability of substrates and the activity of enzymes that deliver substrates to Rubisco (e.g. carbonic anhydrase) can also have a significant effect on the rate of photosynthetic fixation of inorganic carbon, as shown for symbiotic dinoflagellates in sea anemones (Weis 1993). The light-dependent modulation of Rubisco activity has also been established in terrestrial plant studies (for review, see Geiger \& Servaites 1994). Flux through the Calvin-Benson cycle varies with irradiance through changes in the activation-state of Rubisco and at least 2 other light-activated enzymes, phosphoribulokinase (EC 2.7.1.19) and glyceraldehyde 3-phosphate dehydrogenase (EC 1.2.1.13). Changes are of the order of magnitude that would match the changes seen in the symbiotic dinoflagellates over the course of the day. For example, in the study of Sage et al. (1993), the ratio of initial to fully activated Rubisco activity declined by 40 to $50 \%$ within 60 min of light reduction in 2 species of higher plants. These changes were due to the decarbamylation of Rubisco as a regulatory response to the reduction in light. Measuring changes in the activation-state of Rubisco in symbiotic dinoflagellates is exceptionally difficult given the inherent instability of the unusual Rubisco II found in symbiotic dinoflagellates (Whitney \& Yellowlees 1995). However, initial studies over the diel cycle indicate that the expression of Rubisco II does not change in symbiotic dinoflagellates from Tridacna gigas (D. Yellowlees, James Cook University, pers. comm.) However, nothing is known as to the activation state of the enzyme over diel cycle or how putative carbon concentrating mechanisms (Yellowlees pers. comm.) might affect the flux of energy through the Calvin-Benson cycle.
The second possible explanation for the change in ETR in the 2 species over the day is that Rubisco II could function more as an oxygenase (photorespiration) as opposed to a carboxylase. Oxygenase activity as a possible means of photoprotecting photosystems has been seen in some higher plant studies (for review, see Walker 1992, Bichler \& Fock 1996, Heber et al. 1996). Lovelock \& Winter (1996), for example, estimated that excess excitations were mainly processed through this pathway in light-exposed, outer-canopy leaves of several species of tropical rainforest trees. The contribution of other pathways like the MehlerAscorbate Peroxidase cycle (MAP cycle) was estimated to represent only 10 to $20 \%$ of the $\mathrm{CO}_{2}$-independent electron transport. The oxygen respirometry data collected during the present study allows some crucial insight into whether added oxygenase activity by Rubisco II can explain the light-related increases in the electron transport of symbiotic dinoflagellates. Although electron transport is almost double in the middle of the day as opposed to just prior to sunrise, the rates of net oxygen flux measured at same time do not vary (Fig. 9b). This tends to mitigate the possibility that photorespiration by Rubisco II oxygenase activity has been stimulated, as this would lead to higher rates of oxygen consumption and hence a lower net outward oxygen flux in the light. To achieve the doubling of electron transport observed, the respiratory fluxes would almost completely annihilate outward oxygen fluxes. This did not happen. Some caution, however, should be exercised here. The methods used to measure oxygen fluxes have an inherent time delay and may fail to measure the responses measured by PAM fluorometry. In the latter case, measurements are made over time resolutions on the order of seconds, while it takes at least 30 min to obtain a flux measurement. As changes in the maximum quantum yield are likely to be dynamic on shorter time scales, the methods used to measure oxygen flux may lead to the failure to measure the changes seen by the PAM fluorometer

The third possibility is that light-adapted symbiotic dinoflagellates may have greater ETR through nonRubisco catalysed pathways (Foyer et al. 1994). In this case, pathways in which oxygen is the ultimate electron acceptor such as the MAP cycle could be stimulated in response to the greater need to dissipate energy away from the photosystems under high light conditions (Schreiber \& Neubauer 1990, Neubauer \& Yamamoto 1992, Henning et al. 1993, Cheeseman et al. 1997. Geel et al. 1997). In the MAP cycle, oxygen reduction results in superoxide and $\mathrm{H}_{2} \mathrm{O}_{2}$ production, catalysed by superoxide dismutase (SOD). $\mathrm{H}_{2} \mathrm{O}_{2}$ is then reduced by ascorbate in a reaction catalysed by ascorbate peroxidase (ASPX). The monodehydroascorbate 
(MDA) radical that is formed by the ASPX reaction also acts an electron acceptor regenerating ascorbate. The MAP cycle provides a valve reaction in which $\mathrm{O}_{2}$ and $\mathrm{H}_{2} \mathrm{O}_{2}$ (via MDA) serve as electron acceptors, and may also lead to down-regulation of PSII by causing acidification of the thylakoid lumen (Schreiber \& Neubauer 1990). As with changes in Rubisco, the responses here could also be related to the expression and/or activation-state of the enzymes, or to the concentration of substrates like ascorbate in the chloroplast. The existence of elements of the MAP cycle has been known for some time in investigations of oxidative stress in symbiotic dinoflagellates and their coral hosts (Shick \& Dykens 1985, Shick et al. 1995). SOD is the metalloenzyme responsible for catalysing the conversion of superoxide into $\mathrm{H}_{2} \mathrm{O}_{2}$ after the initial formation of superoxide near PSI. The $\mathrm{Cu}$ and $\mathrm{Zn}$ containing forms of SOD are sensitive to cyanide $\left(\mathrm{CN}^{-}\right)$and are associated with the chloroplast stroma (Salin 1987). $\mathrm{CN}^{-}$sensitive SOD decreases with depth (from 3 to $30 \mathrm{~m}$ ) in the symbiotic dinoflagellates of at least 1 species of Acropora (Shick et al. 1995). Similar decreases in the enzymes, catalase and $\mathrm{ASPX}_{1}$ which are responsible for converting $\mathrm{H}_{2} \mathrm{O}_{2}$ into $\mathrm{H}_{2} \mathrm{O}$ and $\mathrm{O}_{2}$, also occurred in the same samples of symbiotic dinoflagellates. Experiments on cultured symbiotic dinoflagellates (Symbiodinium burmudense, Lesser 1996) have revealed strong responses in SOD and ASPX when cultures are exposed to UV as opposed to being protected from it. These responses are increased at higher temperatures. High culture temperature alone induced higher levels of SOD and ASPX activity (Lesser 1996). These results taken together with those from the higher plant literature suggest that the components of the superoxide scavenging system in symbiotic dinoflagellates are likely to respond to increased PAR, and in this way provide extra capacity for electron transport via the MAP cycle. Changes in the activity of either carbon fixation via the Calvin-Benson cycle or the MAP cycle pathway are good candidates for explaining why ETR increase in symbiotic dinoflagellates from corals sampled in the early afternoon

\section{Ecological implications}

Photoinhibition is a part of the daily challenges faced by most photosynthetic organisms (Walker 1992, Long et al. 1994). Light, while beneficial, may lead to the over-reduction of components of the electron transport chain when in excess. This may lead to the increased production of superoxide or singlet oxygen, and eventually to oxidative damage. Initial studies of symbiotic dinoflagellates presented a different picture. Whereas macroalgae consistently showed a decline in dark- adapted $F_{\mathrm{v}} / F_{\mathrm{m}}$ and oxygen evolution rates at high light intensities (for example, Hanelt et al. 1993), symbiotic dinoflagellates in symbiotic anemones (Muller-Parker 1984) and corals (Downton et al. 1976) appeared originally to be immune to the effects of high light. These rates are consistent with those of the present study that show no decline in photosynthetic oxygen flux. The resolution of this feature of respirometry studies of algal cnidarian symbioses may lie in their complex structure. Photosynthetic studies of symbiotic dinoflagellates while resident in corals and other cnidarians are complicated by the typically dense morphology of these associations. Light levels vary by as much as 50 fold from sites within a colony to sites located at the tips of the branches (Titlyanov 1991). Light levels are likely to vary considerably within the coral tissues as a result of algal self-shading, especially when the coral is in a retracted state (Lasker 1979). The consequences of this for whole-colony photosynthetic studies are that rate measurements represent the integration of both saturated and unsaturated sites within a colony or tissues. Consequently, photoinhibitory decreases as light levels are increased are likely to be offset by the higher rates of photosynthesis stemming from the increased penetration of light to the more shaded sites within a colony.

Pink colour morphs of Stylophora pistillata contain the hydrophilic protein-dimer pocilloporin (Dove et al. 1995). The physiological function of pocilloporin is not known, although its expression within Pocillopora damicornis is inducible by PAR as opposed to UV light (Takabayashi \& Hoegh-Guldberg 1995). It is not clear, however, whether pocilloporin acts as a photoprotectant (Dove et al. 1995). The present study has revealed that both pink and brown colour morphs of $S$. pistillata displayed remarkably similar degrees of photoinhibition and recovery. The function of pocilloporin remains equivocal and is currently under intense study.

Symbiotic dinoflagellates appear to have different abilities with regard to accommodating the large fluctuations of PAR in their habitats (Warner et al. 1996). Warner et al. (1996) reported that symbiotic dinoflagellates from the Caribbean coral Siderastrea radians were better able to use NPQ to reduce the damage to photosystems during heat exposure than symbiotic dinoflagellates from Montastrea annularis. In the present study, there are also differences between the symbiotic dinoflagellates from the 2 species of corals with respect to the extent to which $N P Q$ develops during light exposure. It is interesting to speculate that if Fitt \& Warner (1995) and Warner et al. (1996) (see also Lesser 1996) are correct in their conclusions then symbiotic dinoflagellates with greater abilities to deploy NPQ should be more resistant to thermally related bleaching. Energy-dependent regulation of photosyn- 
thetic electron transport is emerging as an important process by which symbiotic dinoflagellates may reduce the impact of heat-stress-related declines in electron processing within the dark reactions of photosynthesis (coral bleaching, Hoegh-Guldberg \& Smith 1989b, Jones et al. 1998). The differences in susceptibility among symbiotic dinoflagellates seen in this study are supported by field studies which show that corals in the family Poritidae are much less likely to bleach than corals from the families Acroporidae or Pocilloporidae (e.g. Hoegh-Guldberg \& Salvat 1995).

Acknowledgements. The authors would like to acknowledge the capable and ready help of Mr Mark Waugh and Ms Robyn Sweetapple-Waugh, who managed One Tree Island Research. Station during the period of this study. We also thank the comments of 2 anonymous reviewers and the excellent editorial assistance of Dr George Humphrey.

\section{LITERATURE CITED}

Ambarsari I, Brown BE, Barlow RG, Britton G, Cummings D (1997) Fluctuations in algal chlorophyll and carotenoid pigments during solar bleaching in coral Goniastrea aspera at Phuket, Thailand. Mar Ecol Prog Ser 159:303-307

Arsalane W, Rousseau B, Duval JC (1994) Influence of the pool size of the xanthophyll cycle on the effects of light stress in a diatom - competition between photoprotection and photoinhibition. Photochem Photobiol 60:237-243

Asada K, Takahashi M (1987) Production and scavenging of active oxygen in photosynthesis. In: Kyle DJ, Osmond CB, Arntzen CJ (eds) Photoinhibition. Elsevier Science Publishers, Amsterdam, p 227-287

Banazak AT, Trench RK (1995) Effects of ultraviolet (UV) radiation on marine microalgal-invertebrate symbioses. 1. Response of the algal symbionts in culture and in hospite. J Exp Mar Biol Ecol 194:213-232

Bichler K, Fock H (1996) Evidence for the contribution of the Mehler-peroxidase reaction in dissipating excess electrons in drought-stressed wheat. Plant Physiol 112: $265-272$

Bukhov NG, Wiese C, Neimanis S, Heber U (1996) Control of photosystem II in spinach leaves by continuous light and by light pulses given in the dark. Photosynth Res 50: $181-191$

Chalker BE, Barnes DJ, Dunlap WC, Jokiel PL (1988) Light and reef-building corals. Interdisc Sci Rev 13:222-237

Cheeseman JM, Herendeen LB, Cheeseman AT, Clough BF (1997) Photosynthesis and photoprotection in mangroves under field conditions. Plant Cell Environ. 20:579-588

Davies PS (1991) Effect of daylight variations on the energy budgets of shallow-water corals. Mar Biol 108:137-144

Dermmig-Adams B, Adams WW, Winter $\mathrm{K}$, Meyer A, Schreiber U, Periera JS, Kruger A, Czygan FC, Lange OL (1989) Photochemical efficiency of photosystem II, photon yield of $\mathrm{O}_{2}$ evolution, photosynthetic capacity, and carotenoid composition during the midday depression of net $\mathrm{CO}_{2}$ uptake in Arbutus unedo growing in Portugal. Planta 177:377-387

Dove S, Takabayashi M, Hoegh-Guldberg O (1995) Isolation and partial characterisation of the pink and blue pigments of pocilloporid and acroporid corals. Biol Bull 189:288-297
Downton WJS, Bishop DG, Larkum AWL, Osmond CB (1976) Oxygen inhibition of photosynthetic oxygen evolution in marine plants. Aust J Plant Physiol 3:73-79

Duysens LNM, Sweers HE (1963) The mechanism of two photochemical reactions in algae studied by means of fluorescence. In: Studies of microalgae and photosynthetic bacteria. University of Tokyo Press, Tokyo, p 353-372

Falkowski PG, Dubinsky Z (1980) Light-shade adaptation of Stylophora pistillata, a hermatypic coral from the Gulf of Eilat. Nature 289:172-174

Falkowski PG, Greene R, Kolber Z (1994) Light utilization and photoinhibition of photosynthesis in marine phytoplankton. In: Baker NR, Bowyer JR (eds) Photoinhibition of photosynthesis: from molecular mechanisms to the field. BIOS Scientific Publishers, Oxford, p 407-430

Fitt WK, Warner ME (1995) Bleaching patterns of four species of Caribbean reef corals. Biol Bull 187:298-307

Foyer CH, Lelandais $M$, Kunert KJ (1994) Photooxidative stress in plants. Physiol Plant 92:696-717

Franklin LA, Levavasseur G, Osmond CB, Henley WJ (1992) Two components of the onset and recovery during photoinhibition of Ulva rotundata. Planta 186:399-408

Franklin LA, Seaton GGR, Lovelock CE, Larkum AWD (1996) Photoinhibition of photosynthesis on a coral reef. Plant Cell Environ 19:825-836

Geel C, Versluis W. Snel JFH (1997) Estimation of oxygen evolution by marine phytoplankton from measurement of the efficiency of Photosystem Il electron flow. Photosynth Res 51:61-70

Geiger DR, Servaites JC (1994) Dynamics of self-regulation of photosynthetic carbon metabolism. Plant Physiol Biochem 32:173-183

Gleason DF (1993) Differential effects of ultraviolet radiation on green and brown morphs of the Caribbean coral Porites astreoides. Limnol Oceanogr 38:1452-1463

Gleason DF, Wellington GM (1993) Ultraviolet radiation and coral bleaching. Nature 365:836-837

Goiran C, Al-Moghrabi S, Allemand D, Jaubert J (1996) Inorganic carbon uptake for photosynthesis by the symbiotic coral/dinoflagellate association. I. Photosynthetic performances of symbionts and dependence on sea water bicarbonate. J Exp Mar Biol Ecol 199:207-225

Hanelt D, Huppertz K, Nultsch W (1993) Daily course of photosynthesis and photoinhibition in marine macroalgae investigated in the laboratory and field. Mar Ecol Prog Ser $97: 31-37$

Harland AD, Davies PS (1995) Symbiont photosynthesis increases both respiration and photosynthesis in the symbiotic sea anemone Anemonia viridis. Mar Biol 123:715-722

Heber U, Gerst U, Kreiger A, Neimanis S, Kobayashi Y (1996) Coupled cyclic electron transport in intact chloroplasts and leaves of $\mathrm{C} 3$ plants: does it really exist? If so, what is its function? Photosynth Res 46:269-275

Henley WJ, Lindley ST, Levavasseur G, Osmond CB, Ramus J (1992) Photosynthetic response of Ulva rotundata to light and temperature during emersion on an intertidal sand flat. Oecologia 89:516-523

Henning H, Neubauer C. Asada K, Schreiber U (1993) Intact chloroplasts display pH5 optimum of $\mathrm{O}_{2}$-reduction in the absence of methyl viologen: indirect evictence for a regulatory role of superoxide protonation. Photosynth Res 37 $69-80$

Hoegh-Guldberg O, Salvat B (1995) Periodic mass bleaching of reef corals along the outer reef slope in Moorea, French Polynesia. Mar Ecol Prog Ser 121:181-190

Hoegh-Guldberg O, Smith GJ (1989a) The influence of the population density of zooxanthellae and supply of ammo- 
nium on the biomass and metabolic characteristics of the reef corals Seriatopora hystrix (Dana 1846) and Stylophora pistillata (Esper 1797). Mar Ecol Prog Ser 57:173-186

Hoegh-Guldberg O, Smith GJ (1989b) The effect of sudden changes in temperature, irradiance and salinity on the population density and export of zooxanthellae from the reef corals Stylophora pistillata (Esper 1797) and Seriatopora hystrix (Dana 1846). J Exp Mar Biol Ecol 129: $279-303$

Horton P, Ruban A (1994) The role of light harvesting complex Il in energy quenching. In: Baker NR, Bowyer JR (eds) Photoinhibition of photosynthesis: from molecular mechanisms to the field. BIOS Scientific Publishers, Oxford, p 111-128

Johannes RE, Wiebe WJ (1970) A method for determination of coral tissue biomass and composition. Limnol Oceanogr 21:540-547

Johnson G, Sakshaug E (1993) Biooptical characteristics and photoadaptive responses in the toxic and bloom-forming dinoflagellates Gyrodinium aureolum, Gymnodinium galatheanum, and two strains of Prorocentrum minimum. J Phycol 29:627-642

Jokiel PL (1980) Solar ultraviolet radiation and coral reef epifauna. Science 207:1069-1071

Jokiel PL, York RH (1982) Solar ultraviolet photobiology of the reef coral Pocillopora damicornis and symbiotic zooxanthellae. Bull Mar Sci 32:301-315

Jones R, Hoegh-Guldberg O, Larkum AWD, Schreiber U (1998) Temperature induced bleaching of corals begins with impairment of dark metabolism in zooxanthellae. Plant Cell Environ 21:1219-1230

Kinzie RA (1993) Effects of ambient levels of solar ultraviolet radiation on zooxanthellae and photosynthesis of the reef coral Montipora verrucosa. Mar Biol 116:319-327

Kok B (1956) On the inhibition of photosynthesis by intense light. Biochim Biophys Acta 21:234-244

Krause $\mathrm{GH}$, Weis $\mathrm{H}$ (1991) Chlorophyll fluorescence: the basics. Annu Rev Plant Physiol Plant Mol Biol 42:313-349

Lasker HR (1979) Light-dependent activity patterns among reef corals: Montastrea annularis. Biol Bull 156:196-211

Lesser MP (1989) Photobiology of natural populations of zooxanthellae from the sea anemone Aiptasia pallida: assessment of the host's role in protection against ultraviolet radiation. Cytometry 10:653-658

Lesser MP (1996) Elevated temperatures and ultraviolet radiation cause oxidative stress and inhibit photosynthesis in symbiotic dinoflagellates. Limnol Oceanogr 41:271-283

Long SP, Humphries S, Falkowski PG (1994) Photoinhibition of photosynthesis in nature. Annu Rev Plant Physiol Plant Mol Biol 45:633-662

Lovelock CE. Winter K (1996) Oxygen dependent electron transport and protection from photoinhibition in leaves of tropical tree species. Planta 198:580-587

Muller-Parker G (1984) Photosynthesis-irradiance response and photosynthetic periodicity in the sea anemone Aiptasia pulchella and its zooxanthellae. Mar Biol 82:225-232

Neubauer C, Yamamoto HY (1992) Mehler-peroxidase reaction mediates zeaxanthin formation and zeaxanthinrelated fluorescence quenching in intact chloroplasts. Plant Physiol 99:1354-1361

Olaizola M. Yamamoto HY (1994) Short-term response of the diadinoxanthin cycle and fluorescence yield to high irradiance in Chaetoceros muelleri (Bacillariophyceae). J Phy$\operatorname{col} 30: 606-612$

Olaizola M, Laroche J, Kolber Z, Falkowski PG (1994) Nonphotochemical fluorescence quenching and the diadinoxanthin cycle in a marine diatom. Photosynth Res 41 . $357-370$
Osmond CB (1994) What is photoinhibition: some insights from comparisons of sun and shade plants. In: Baker NR, Bowyer JR (eds) Photoinhibition of photosynthesis: from molecular mechanisms to the field. BIOS Scientific Publishers, Oxford, p 95-110

Osmond CB, Grace SC (1995) Perspectives on photoinhibition and photorespiration in the field: quintessential inefficiencies of the light and dark reactions of photosynthesis? J Exp Bot 46:1351-1362

Rhiel E, Marquardt J, Eppard M, Morschel E, Krumbein WE (1997) The light harvesting system of the diatom Cyclotella cryptica - isolation and characterization of the main light harvesting complex and evidence for the existence of minor pigment proteins. Bot Acta 110:109-117

Sage RF, Reid CD, Moore BD, Seemann JR (1993) Long-term kinetics of the light-dependent regulation of ribulose-1,5bisphosphate carboxylase oxygenase activity in plants with and without 2-carboxyarabinitol 1-phosphate. Planta 191:222-230

Salin ML (1987) Toxic oxygen species and protective systems of the chioroplast. Physiol Plant 72:681-689

Schreiber U, Bilger W (1987) Rapid assessment of stress effects on plant leaves by chlorophyll fluorescence measurements. In: Tenhunen JD et al. (eds) Plant responses to stress. Springer Verlag, Berlin

Schreiber $U$, Neubauer $\mathrm{C}(1990) \mathrm{O}_{2}$-dependent electron flow, membrane energization and the mechanism of non-photochemical quenching of chlorophyll fluorescence. Photosynth Res 25:279-293

Schreiber U, Bilger W, Neubauer C (1994) Chlorophyll fluorescence as a nonintrusive indicator for rapid assessment of in vivo photosynthesis. In: Schulze ED, Caldwell MM (eds) Ecophysiology of photosynthesis. Springer-Verlag, Berlin, p 49-70

Schreiber U, Kuhl M, Klimant I, Reising H (1996) Measurement of chlorophyll fluorescence within leaves using a modified PAM fluorometer with a fibre-optic microprobe. Photosynth Res 47:103-109

Schreiber U, Gademan R, Ralph PJ, Larkum AWD (1997) Assessment of photosynthetic performance of Prochloron in Lissoclonium patella in hospite by chlorophyll fluorescence measurements. Plant Cell Physiol 38:945-951

Shick JM, Dykens JA (1985) Oxygen detoxification in algalinvertebrate symbioses from the Great Barrier Reef. Oecologia 66:33-41

Shick JM, Lesser MP, Stochaj WR (1991) Ultraviolet radiation and photooxidative stress in zooxanthellate Anthozoa: the sea anemone Phyllodiscus semoni and the octocoral Clavularia sp. Symbiosis 10:145-173

Shick JM, Lesser MP, Dunlap WC, Stochaj WR, Chalker BE, Wu Won J (1995) Depth dependent responses to solar ultraviolet radiation and oxidative stress in the zooxanthellate coral Acropora microphthalma. Mar Biol 122: 41-51

Shick JM, Lesser MP, Jokiel PL (1996) Effects of ultraviolet radiation on corals and other coral reef organisms. Global Change Biol 2:527-545

Styring S, Jegerschöld C (1994) Light-induced reactions impairing electron transfer through photosystem II. In: Baker NR, Bowyer JR (eds) Photoinhibition of photosynthesis: from molecular mechanisms to the field. BIOS Scientific Publishers, Oxford, p 51-74

Takabayashi M. Hoegh-Guldberg O (1995) The ecological and physiological differences between two colour morphs of the coral Pocillopora damicornis. Mar Biol 123:705-714

Telfer A, Barber J (1994) Elucidating the molecular mechanisms of photoinhibition by studying isolated photosystem 
II reaction centres. In: Baker NR, Bowyer JR (eds) Photoinhibition of photosynthesis: from molecular mechanisms to the field. BIOS Scientific Publishers, Oxford, p 25-50

Titlyanov EA (1991) Light adaptation and production characteristics of branches differing by age and illumination of the hermatypic coral Pocillopora verrucosa. Symbiosis 10 249-260

Vassiliev IR, Prasil O, Wyman KD, Kolber Z, Hanson AK, Prentice JE, Falkowski PG (1994) Inhibition of PSII photochemistry by PAR and UV radiation in natural phytoplankton communities. Photosynth Res 42:51-64

Walker D (1992) Tansley review No. 36. Excited leaves. New Phytol 121:325-345

Warner ME, Fitt WK, Schmidt GW (1996) The effects of elevated temperature on the photosynthetic efficiency of zooxanthellae in hospite from four different species of

Editorial responsibility: George Humphrey (Contributing Editor), Sydney, Australia reef coral: a novel approach. Plant Cell Environ 19 $291-299$

Weis VM (1993) Effect of dissolved inorganic carbon concentration on the photosynthesis of the symbiotic sea anemone Aiptasia pulchella (Carlgren): role of carbonic anhydrase. J Exp Mar Biol Ecol 174:209-225

Whitney SM, Yellowlees D (1995) Preliminary investigations into the structure and activity of ribulose bisphosphate carboxylase from two photosynthetic dinoflagellates. J Phycol 31:138-146

Wyman KD, Dubinsky Z, Porter JW, Falkowski PG (1987) Light absorption and utilization among hermatypic corals: a study in Jamaica, West Indies. Mar Biol 96:283-292

Young AJ, Frank HA (1996) Energy transfer reactions involving carotenoids - quenching of chlorophyll fluorescence. J Photochem Photobiol Biol 36:3-15

Submitted: May 22, 1998; Accepted: February 26, 1999 Proofs received from author(s): June 24, 1999 